\section{POS0061-PARE HOW DO THE COMPLICATIONS OF SPONDYLOARTHRITIS (SPA*) IMPACT THE QUALITY OF LIFE (QOL) OF PATIENTS LIVING WITH SPA?}

S. Patenaude ${ }^{1}$, W. Gerhart ${ }^{2} .{ }^{1}$ Canadian Spondylitis Association, Intern, Phelpston, Canada; ${ }^{2}$ Canadian Spondylitis Association, Executive Director, Phelpston, Canada

Background: SpA describes a group of chronic inflammatory arthritic diseases with common features, including inflammation of the spine, eyes, skin and gastrointestinal tract. These conditions can be painful and debilitating for many. Delayed diagnosis and treatment can lead to irreversible damage to the spine and other joints. Diagnosis of these conditions can take, on average, 7 years or more. We don't know what causes SpA and there is no cure. The onset of symptoms can be in early childhood and expands throughout one's lifespan. It affects children, women and men worldwide.

Objectives: To understand how the complications of living with SpA impacts QOL as well as what is important to patients in order to help the CSA ${ }^{\star *}$ prioritize advocacy focus and resource development.

Methods: The CSA surveyed the community virtually from 11/19/19 to 01/21/20. The results of 838 respondents were analyzed after the survey closed. 466 participants responded to the questions regarding complications.

Results: In total, participants had an average of 3.3 complications. Those living with ankylosing spondylitis experienced an average of 3.5 while those with psoriatic arthritis reported an average of 3.9

Sleep issues $(65 \%)$, chronic pain $(63 \%)$, and combined depression and anxiety $(56 \%)$ were the most prevalent conditions reported among participants. In addition, $23 \%$ said they live with inflammatory bowel disease. Other complications include uveitis, weight issues, migraine, vertebral disc herniations and hypertension.

Those who reported weight issues (over $44 \%$ ) consequently had increased anxiety, depression and chronic pain compared to those without weight issues.

Over $65 \%$ reported experiencing sleep issues. Many $(26 \%)$ said that nothing helps with their sleep. Others used cannabis $(24 \%)$, prescribed sleeping pills $(20 \%)$ and exercise $(19 \%)$ to cope.

$36 \%$ of participants said that they suffer from chronic fatigue syndrome. When asked how they manage their fatigue, the most common answer was exercise. Most participants said they have yet to find something that helps them efficiently manage their fatigue.

Over 400 people said they suffer from either depression or anxiety, or both. When asked how they cope with this, $40 \%$ said talking to loved ones. Exercise to cope was reported by $32 \%$ and $31 \%$ take prescription medication. Those who suffer from Psoriasis experienced a higher prevalence of anxiety and depression.

Conclusion: Overall, the presence of complications is an additional stressor to SpA patients. Many pointed out that the complications are sometimes more burdensome than the actual SpA condition and some patients even prioritize the management of the complications over the actual SpA condition. These complications can lead to increased trips to the physician resulting in more healthcare interventions and medications, causing frustration to patients.

Only $59 \%$ of respondents mentioned that their rheumatologist regularly asks them about additional complications such as depression, fatigue and gut issues. Many felt that their rheumatologist seems to be more concerned with pain management and continuing function and do not necessarily address other health concerns and complications, particularly mental health. Although these are often overlooked, it is clear that complications have a significant impact on patient health and overall QOL.

The CSA is committed to developing programs and resources to help patients manage all the complications commonly experienced to improve health outcomes and overall QOL.

It doesn't have to be visible to be real. Together we are stronger! REFERENCES:

[1] SpA conditions include: Ankylosing Spondylitis, Psoriatic Arthritis, non-radial $\mathrm{SpA}$, Axial SpA, Peripheral Spondyloarthritis, Enteropathic Arthritis, Reactive Arthritis and Juvenile Onset Arthritis

[2] The Canadian Spondylitis Association (CSA) is a national non-profit patient association supporting and advocating for those living with $\mathrm{SpA}$.

Disclosure of Interests: None declared.

DOI: 10.1136/annrheumdis-2021-eular.1611

\section{POS0062-PARE REAL-WORLD PATIENT EXPERIENCE AND TREATMENT PREFERENCES IN PATIENTS WITH PSORIATIC ARTHRITIS}

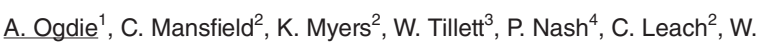
B. Nowell ${ }^{5}$, K. Gavigan ${ }^{6}$, P. Zueger ${ }^{7}$, E. Mcdearmon-Blondell ${ }^{8}$, J. A. Walsh ${ }^{9,10}$ ${ }^{1}$ Perelman School of Medicine, University of Pennsylvania, Department of Medicine, Philadelphia, United States of America; ${ }^{2}$ RTI Health Solutions, Health Preference Assessment, Research Triangle Park, United States of
America; ${ }^{3}$ Royal National Hospital for Rheumatic Diseases, Department of Rheumatology, Bath, United Kingdom: ${ }^{4}$ Griffith University, Department of Medicine, Brisbane, Australia; ${ }^{5}$ Global Healthy Living Foundation, PatientCentered Research, Upper Nyack, United States of America; ${ }^{6}$ Global Healthy Living Foundation, Research and Data Science, Upper Nyack, United States of America: ${ }^{7} \mathrm{AbbVie}$, Global Rheumatology, Chicago, United States of America; ${ }^{8} \mathrm{AbbVie}$, Global Medical Affairs, Chicago, United States of America; ${ }^{9}$ University of Utah School of Medicine, Division of Rheumatology, Salt Lake City, United States of America; ${ }^{10}$ George E. Wahlen Veteran Affairs Medical Center, Rheumatology, Salt Lake City, United States of America

Background: Despite recent advances in the treatment of psoriatic arthritis (PsA), many patients experience inadequate response or intolerance to therapy, indicating that unmet treatment-related needs remain. An understanding of patients' experience with PsA and its treatment is needed to bring the patient's perspective into treatment decision-making and development of new therapies. Objectives: To better understand real-world PsA patients' experience with PsA via evaluation of (1) the burden and importance of common PsA symptoms and disease impacts and (2) treatment preferences.

Methods: A cross-sectional, web-based survey was developed, informed by published literature and treatment guidelines, expert clinical opinion, and cognitive debriefing interviews with PsA patients. Adults with a self-reported diagnosis of PsA were recruited from a US rheumatology patient-centered research registry and other online patient communities. Object case best-worst scaling (BWS was used to evaluate the relative burden of 11 PsA-related symptoms and the relative importance of improvement in 9 PsA-related disease impacts. BWS data were analyzed using a random parameters logit model. Data on patient demographics and preferences for PsA treatment attributes, including experience with methotrexate and preference for route and frequency of administration, were analyzed descriptively.

Results: The sample of 247 respondents was $79 \%$ female, had a mean age of 53.4 years (range 24-79 years), and had a mean time since PsA diagnosis of 9.4 years, with $86 \%$ currently being treated by a rheumatologist. The most common PsA symptoms ever experienced were joint pain, morning

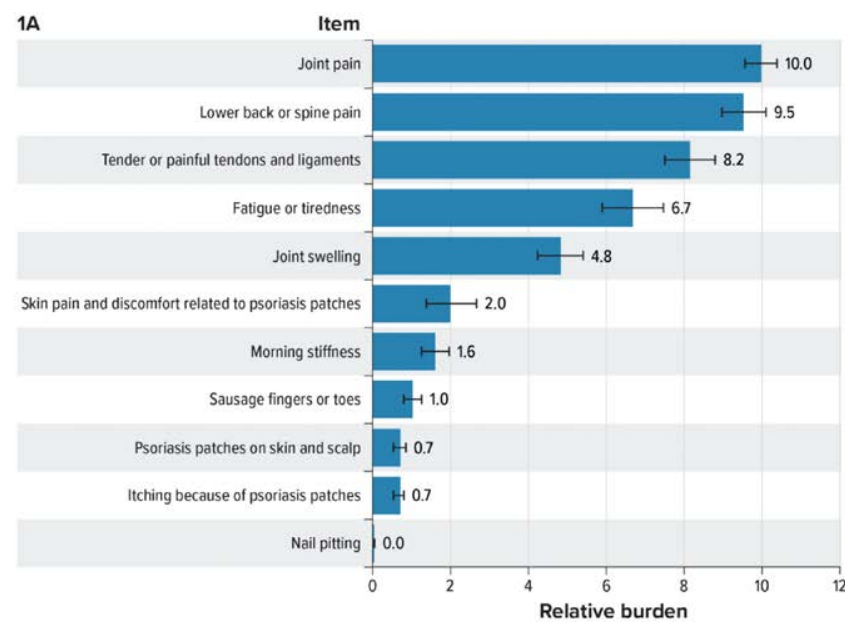

18

Item

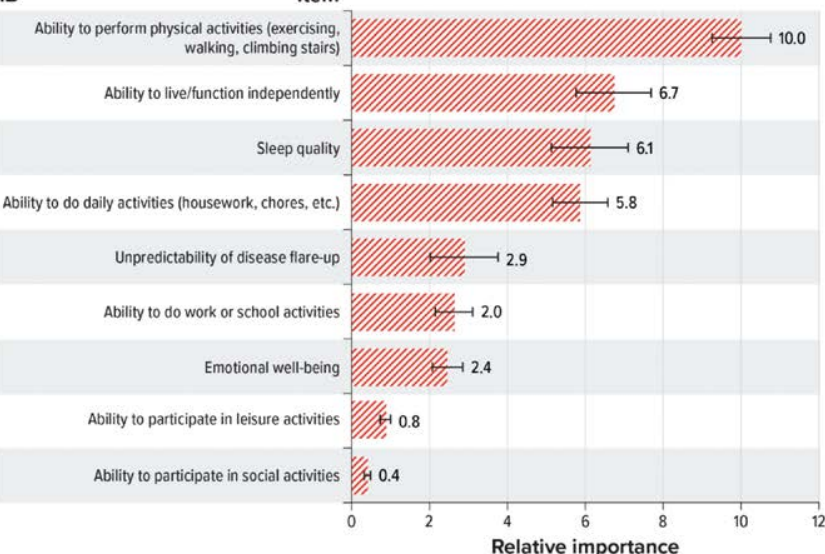

Note: Figure 1 presents the BWS relative burden and importance estimntes for the full somple rescaled such that the most burdensome sympton joint pain (1A), and the most important impact to improve, ablity to perform physical activities (18), are set to 10. In Figure $1 \mathrm{~A}$, the scaled relative burden weights for each of the remaining items can be interpreted as the effect of that them on utility relative to the utilin of joint pain, while in Figure 1B, the scaled relative importance weights for each of the remaining items can be interpreted as the effect of that tem on utility relative to 政 
stiffness and fatigue, while the least common symptom was skin pain/discomfort related to psoriasis patches. In the BWS, patients reported pain-related symptoms (i.e., joint pain and lower back or spine pain) as the most bothersome, while the least bothersome symptoms were psoriasis-related (Figure 1). Patients reported ability to perform physical activities as the most important disease impact to improve, followed by ability to live/function independently, sleep quality, and ability to do daily activities. Nearly half the sample (49\%) stated they would strongly prefer a treatment for PsA that does not include methotrexate. Among patients who were not satisfied with methotrexate, the top reason was dislike of the short-term side effects after each dose. When asked to choose among four different ways of taking their PsA medication (oral once a day, oral twice a day, injection every 2 weeks, injection once a month), the most preferred method was oral once a day (38\%) followed by injection once a month (26\%), with $24 \%$ indicating no preference. Additionally, $49 \%$ of the sample felt that mode of administration was an important factor when deciding to start a new therapy.

Conclusion: Among real-world patients with PsA, the most bothersome PsA symptoms were related to pain while patients most wanted to improve functional impacts of their disease. Patients most preferred an oral once a day treatment option and treatment regimens that do not include methotrexate. These findings can serve to better inform development of new therapies and guide shared patient-provider treatment decision making.

Disclosure of Interests: Alexis Ogdie Consultant of: Abbvie, Amgen, BMS, Celgene, Corrona, Gilead, Janssen, Lilly, Novartis, Pfizer, UCB, Grant/research support from: Pfizer to Penn, Novartis to Penn, Amgen to Forward/NDB.

Royalties: Novartis to husband, Carol Mansfield: None declared, Kelley Myers: None declared, William Tillett Speakers bureau: AbbVie, Amgen, Celgene, Lilly, Janssen, Novartis, Pfizer Inc., and UCB, Consultant of: AbbVie, Amgen, Celgene, Lilly, Janssen, Novartis, MSD, Pfizer Inc., and UCB, Grant/research support from: AbbVie, Celgene, Eli Lilly, Janssen, Novartis, Pfizer Inc, Peter Nash Grant/research support from: Abbvie, Pfizer, Roche, Sanofi, Boerhringer, Lilly, Novartis, BMS, MSD, Janssen, Gilead, and Samsung, Colton Leach: None declared, W. Benjamin Nowell Grant/research support from: AbbVie, Amgen, and Eli Lilly, Kelly Gavigan: None declared, Patrick Zueger Shareholder of: AbbVie, Employee of: AbbVie, Erin McDearmon-Blondell Shareholder of: AbbVie, Employee of: AbbVie, Jessica A. Walsh Consultant of: AbbVie, Amgen, Eli Lilly and Company, Janssen, Merck, Novartis, Pfizer, UCB, Grant/research support from: AbbVie, Merck, Pfizer.

DOI: 10.1136/annrheumdis-2021-eular.852

\section{POS0063-PARE IMPLEMENTING SHARED DECISION MAKING TO ADVANCE PATIENT CENTRED RHEUMATOID ARTHRITIS CARE: A ROLE FOR A PATIENT ORGANISATION}

P. Pennings Msc ${ }^{1}$, H. Voogdt-Pruis ${ }^{2,3}$, B. Maat ${ }^{4}$, T. Foekens ${ }^{4}$, L. J. Kranenburg - van Koppen ${ }^{5}$, A. Pasma ${ }^{5}$, J. Hoes ${ }^{6}$, I. Schoonen-Nuijten7, M. Van den Dikkenberg, $\mathrm{Msc}^{8}$, N. Basoski ${ }^{8}$, A. Weel, ${ }^{8,9}$, G. Willemsen- de Mey Msc ${ }^{1}$ ${ }^{1}$ National Association ReumaZorg Nederland, Patientparticipation and Communication, Nijmegen, Netherlands; ${ }^{2}$ National Association ReumaZorg Nederland, Projectmanager Project Shared Decision Making in RA Care, Nijmegen, Netherlands; ${ }^{3}$ University Medical Centre Utrecht (UMCU), Department of Julius Global Health, Utrecht, Netherlands; ${ }^{4}$ National Association ReumaZorg Nederland, Patientpartner for the department of Patientparticipation and Communication, Nijmegen, Netherlands; ${ }^{5}$ Erasmus Medical Centre, Department of Rheumatology, Rotterdam, Netherlands; ${ }^{6}$ Bravis Medical Centre, Department of Rheumatology, Roosendaal, Netherlands; ${ }^{6}$ Bravis Medical Centre, Department of Rheumatology, Roosendaal, Netherlands; ${ }^{8}$ Maasstad Medical Centre, Department of Rheumatology, Rotterdam, Netherlands; ${ }^{9}$ Erasmus University, Department ESHPM (HTA), Rotterdam, Netherlands

Background: In rheumatoid arthritis (RA) care, patients and professionals face treatment decisions regularly due to the high number of treatment options, the chronic character of the disease and challenges around multi-morbidity. Recent studies have underlined the added value of shared decision making (SDM) between patients and professionals in RA care for health outcomes (i.e. disease activity, pain and joint damage) ${ }^{1-4}$. Therefore, effort is needed to facilitate the implementation of SDM in daily clinical practice in order to advance patient centred RA care.

Objectives: The aim of this implementation project was to improve SDM about treatment options for patients with RA. In addition the use of (Patient Reported) Outcome Measures in the process of SDM was taken into account.

Methods: An implementation programme was developed by the National Association ReumaZorg Nederland (RZN) in co-creation with patientpartners and RMD professionals. Three hospital departments of rheumatology in the Netherlands participated in the project between January 2020 and March 2021. The implementation of SDM was supported by a project team of RZN.
Results: The implementation programme started with the recording of RMD consultations in three participating departments of rheumatology. The consultations were then evaluated on the process of SDM (OPTION5) and discussed during the training of professionals that followed. Three observed improvements in SDM in RA care were: a. A more explicit introduction of choice for a patient is needed during the consultation; $b$. Tasks within the process of SDM should be allocated clearly among RMS specialists and nurses working together, in order to avoid unnecessary repetition of the same - or even inconsistent information; c. Besides the use of (patient reported) outcome measures in the SDM process, it is also important to include patients' values (what matters to them?) when deciding on the best fitting treatment option. After the training, implementation support for SDM was given and aids to support the SDM process (i.e. redesign of health care processes, task allocation, hand card with explanation of the 4 steps of SDM) were developed. The implementation programme was tailored to the needs and stage of change for each hospital. Implementation materials for the hospital teams were developed in co-creation with patientpartners and the professionals At the end of the project, a second set of consultations was recorded and evaluated on SDM. The hospital teams concluded that a continuous improvement cycle is needed to further enhance SDM.

Conclusion: A continuous implementation programme on shared decision making could stimulate the enhancement of patient centred care in daily practice. Patient organisations could take a significant role in such a programme.

\section{REFERENCES:}

[1] Pablos JL et al. Patient. 2020 Feb;13(1):57-69.

[2] Fautrel B et al. Rheumatol Int. 2018 Jun;38(6):935-947. doi: 10.1007/ s00296-018-4005-5.

[3] Mathijssen EGE et al. RMD Open. 2020 Jan;6(1):e001121. doi: 10.1136/ rmdopen-2019-001121.

[4] Nota, I. 2017. Shared Decision-Making in rheumatology: What matters to patients? Thesis, University of Twente.

Acknowledgements: This project of the National Association ReumaZorg Nederland (RZN) was made possible thanks to the effort of the following patientpartners, RMD specialists and researchers within the field of RMDs:

Helene R Voogdt-Pruis, (AP PhD, RZN projectmanager Shared Decision Making within RMD care), Bertha Maat (RZN patient research partner), Theo Foekens (RZN patient research partner), Laura Kranenburg-van Koppen (MD, Msc, rheumatologist Erasmus and IJsselland Medical Centre), Annelieke Pasma (PhD, researcher Erasmus Medical Centre), Jos Hoes (MD PhD, rheumatologist Bravis Medical Centre), Inge Schoonen-Nuijten (RMD nurse, Bravis Medical Centre), Marijke van den Dikkenberg, (MSc, researcher Maasstad Medical Centre), Natalja Basoski (MD MSc, rheumatologist Maasstad Medical Centre), Angelique Weel-Koenders (Prof. Dr., rheumatologist Maasstad Medical Centre, Erasmus University), Gerardine Willemsen- de Mey (MSc, Chair of RZN).

Disclosure of Interests: None declared.

DOI: 10.1136/annrheumdis-2021-eular.1085

\section{POS0064-PARE DESIGN OF AN INNOVATIVE MHEALTH SOLUTION FOR FIGHTING STIGMA ASSOCIATED WITH CHRONIC PAIN}

Y. Koumpouros ${ }^{1}$, K. Antonopoulou ${ }^{2}$, A. Pappa ${ }^{3}$, K. Tsekoura ${ }^{3}$, N. Malliou ${ }^{4}$, M. Salamaliki ${ }^{5}$, E. Oikonomoula ${ }^{6}$, S. Makri ${ }^{7}{ }^{1}$ University of West Attica, Department of Public and Community Health, Athens, Greece; ${ }^{2} \mathrm{Hellenic}$ League Against Rhuematism, Headquarters, Athens, Greece; ${ }^{2}$ Hellenic League Against Rhuematism, Headquarters, Athens, Greece; ${ }^{4}$ Hellenic League Against Rhuematism, Thessaloniki, Thessaloniki, Greece; ${ }^{5}$ Hellenic League Against Rhuematism, Patras, Patras, Greece; ${ }^{6} \mathrm{Hellenic}$ League Against Rhuematism, Thessaly, Trikala, Greece; ${ }^{7}$ Cyrpus League Against Rheumatism, Headquarters, Nicosia, Cyprus

Background: Pain is associated with a plethora of diseases. The statistics reveal that chronic pain affects around 100 million people across Europe and is closely associated with high unemployment rates, depression, substance abuse \& social exclusion. Stigma is a significant and persistent problem for those with chronic pain. Lack of public awareness \& stigma associated with pain affect not only patients but also society.

Objectives: The present research proposes a holistic solution to combat stigma using the latest technological developments. A mobile health application has been designed in order to serve the various stakeholders (patients, families, community) in the field under study. The objective of the final "StigmApp" solution is 4-fold:(i) to facilitate pain management, (ii) to aware the general public, (iii) to educate all different parties \& (iv) to facilitate actions \& research to combat stigma. Another innovative feature is that it delivers the required information to each party in a highly automated, personalized \& digestible way making the whole experience enjoyable, while ensuring user engagement.

Methods: A multidisciplinary team was formed at the beginning of the project in order to ensure the desired outcome. Two patient organizations from Cyprus \& Greece, two behavioral scientists, three physicians, one psychologist, ten 